\title{
INVESTIGATION ON INFLUENCE OF SPEED ON ROLLING RESISTANCE OF BELT CONVEYOR BASED ON VISCOELASTIC PROPERTIES*
}

\author{
Yan Lu, Fu-Yan Lin, Yu-Chao Wang \\ School of Mechanical Electronic \& Information Engineer, \\ China University of Mining and Technology, Beijing, Beijing, 100083, \\ e-mails: mly271515@163.com, lfyly1990@163.com, lylovexlv@163.com
}

[Received 15 April 2015. Accepted 15 June 2015]

\begin{abstract}
Since indentation rolling resistance accounts for the major part of total resistance of belt conveyor, it is important to compute it using a proper method, during the design and application study of the belt conveyor. Firstly, an approximate formula for computing the indentation rolling resistance is offered. In this formula, a one-dimensional Winkler foundation and a three-parameter viscoelastic Maxwell solid model of the belt backing material are used to determine the resistance to motion of a conveyor belt over idlers. The velocity of belt is an important operating parameter in the working conditions of the belt conveyor. What's more, a set of experimental apparatus, which can measure the value of indentation rolling resistance is designed. Author obtains a series of measured data under the different belt speeds with the help of experimental apparatus. Finally, a computation example, that is provided for a typical rubber compound backing material, shows the comparison between the measured and the theoretical results, which offers the influence of speed on the rolling resistance.

KeY wORDS: Viscoelastic property, Maxwell solid model, Winkler foundation, rolling resistance, belt speed.
\end{abstract}

\section{Introduction}

Energy loss due to inelastic deformation and indentation of the belt covering, as it passes over each idler of the system, is generally considered to be dominant loss mechanism in the system. Therefore, predictive analytical model of this loss is thus important to designers of such systems. The particular characteristic of rubber compounds is viscoelastic property, therefore, a useful

\footnotetext{
${ }^{*}$ Corresponding author e-mail: mly271515@163.com
} 
viscoelastic constitutive model must accurately account for the property., The Winkler foundation deformation model is practical, as for the model of rolling resistance.

In S. Vieweg's paper [1], it is mainly concentrated on the dynamic shear properties of styrene-butadiene vulcanizates, filled with carbon black. It is a useful research on the indentation rolling resistance. Jayne I. O'Shea [2] discusses the influence of viscoelastic property measurements on the predicted rolling resistance. In Fletcher's paper [3], it mainly discusses the Non-Linearity property of the viscoelastic material such as rubber. Ulmer [4] points out, that the property of carbon black-filled rubber compounds is strain dependence. Drozdov [5] remind that the Payne effect should not be ignored aimed at polymer. Vieweg $[6,7]$ investigates the dynamic shear property of vulcanizates, filled with carbon black. However, above findings mainly concentrates on the property of viscoelastic material. On the other hand, some researchers mainly carry out further exploration on the mechanical model of contact area between idler and belt. For example, Qiu Xiang Jun $[8,9]$ uses the full two-dimensional model to character the contact stress between idler and belt for rolling resistance. Wang Fan Sheng [10] makes further efforts on the full two-dimensional model, that he uses the differential equation to describe the constitutive behaviour of the incompressible viscoelastic material, instead of integral equation. Besides, the focus of M. Hager, L. Overmeyer's paper [11] is on the influence of the pulley side cover plate compounds on the indentation rolling resistance. In G. Lodewijks's paper [12], it is mainly concentrated on the influence of the mechanic/dynamic properties of rubber measured at a specific rheometer on the indentation rolling resistance. C. Wheeler's paper [13] uses finite element methods to analyze the indentation rolling resistance. H. Lauhoff [14] mainly conducts a research that is - "Speed control on belt conveyors - Dose it really save energy". L. K. Nordell in her paper [15] expound the influence of various running resistance on design of belt conveyor of $20 \mathrm{~km}$. C. O. Jonkers [16] deduce a formula to calculate the indentation rolling resistance with the help of field experience and viscoelastic properties of rubber.

As for this paper, a three-parameter viscoelastic Maxwell solid model is used in combination with the Winkler foundation deformation to infer a formula of indentation rolling resistance. Then, in this paper it selects a fabric belt as an experimental belt to find the connection between speed and rolling resistance. Finally, it compares the measured data from the experimental apparatus with the results from this formula. 


\section{Theory of indentation rolling resistance}

\subsection{The three-parameter viscoelastic Maxwell model and Win- kler foundation}

In generally, the various arrangements of springs and dashpots are often used to reflect the viscoelastic property. What's more, as for the rubber compound, which is often used as backing material for conveyor belt, it is common to use the three-parameter viscoelastic Maxwell solid model to reflect the viscoelastic property. The three-parameter viscoelastic Maxwell model consists of a single spring in parallel with another spring and a dashpot as shown in Fig. 1.

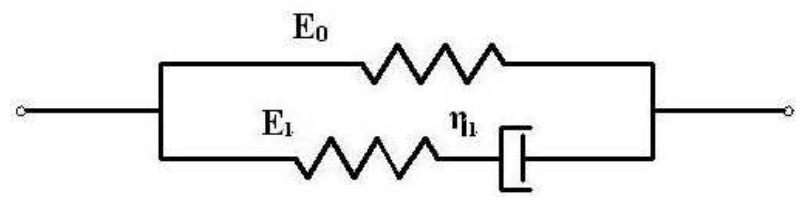

Fig. 1. Mechanical elements of three-parameter Maxwell model

The constants $E_{1}$ and $\eta_{1}$ represent the elastic and dissipative elements of the model. The symbol of $E_{0}$ is referred to the equilibrium modulus.

The relaxation function of the three parameter model is [17]:

$$
\Psi(t)=E_{0}+E_{1} \times \exp (-t / \tau),
$$

where the relaxation time is calculated by [17]:

$$
\tau=\eta_{1} / E_{1}
$$

On the other hand, a convenient approach to determine the pressure distribution at any point of the contact area is to assume, that the backing material can be modelled by one-dimensional Winkler foundation model, see Fig. 2. The viscoelastic foundation of depth $h$ rests on a rigid base and is compressed by the rigid idler. Because of the Winkler foundation model, it implies that shear between adjacent elements of the model is ignored.

\subsection{Rubber properties and material characterization}

Testing in a cyclic mode at various frequencies is a natural way to capture the time dependence through Fourier analysis, because the dissipative materials are inherently time dependent. For a sinusoidal strain history of the form $\varepsilon=\varepsilon_{0} \sin (\omega t), \omega$ is the angular frequency and $\varepsilon_{0}$ is the amplitude. What's more, when the strains experienced by belt covers can routinely be below $0.1 \%$, 


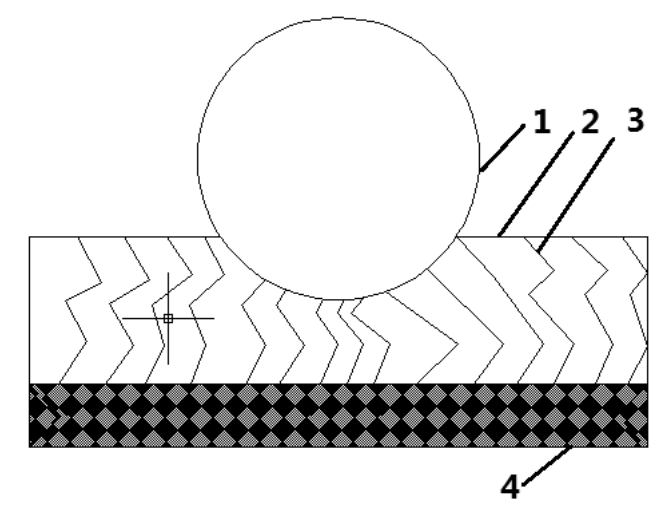

Fig. 2. Winkler foundation model

1. Idler 2. Backing material 3. Spring 4. Rigid base

the property of rubber is characterized as a linear viscoelastic one [17]. As a result, after an initial transitory state, the stress follows the strain in frequency, but at a delayed phase or angle $\delta$. Finally, the one- dimensional stress/strain relationship is of the form [17]:

$$
\sigma(\omega)=E^{*}(\omega) \varepsilon_{0} \sin (\omega t+\delta) .
$$

The stress is expressed by $\sigma(\omega)$ and the magnitude of the complex modulus is denoted by the following equation [17], with real and imaginary components $E^{\prime}(\omega)$ and $E^{\prime \prime}(\omega)$, called the storage and the loss modulii, respectively:

$$
E^{*}(\omega)=\sqrt{\left(E^{\prime}(\omega)^{2}+E^{\prime \prime}(\omega)^{2}\right)}
$$

In this case, the loss factor $\tan (\delta)$ is defined by [17]:

$$
\tan (\delta)=\frac{E^{\prime \prime}}{E^{\prime}}=\frac{\omega \eta_{1} E_{1}^{2}}{E_{0} E_{1}^{2}+\omega^{2} \eta_{1}^{2}\left(E_{1}+E_{0}\right)}
$$

For three-parameter Maxwell model, the storage and the loss modulii of Equation (4) are related to the mechanical element values by the Prony series [17]:

$$
E^{\prime}(\omega)=E_{0}+E_{1} \frac{\omega^{2} \tau^{2}}{1+\omega^{2} \tau^{2}}
$$




$$
E^{\prime \prime}(\omega)=E_{1} \frac{\omega^{2} \tau^{2}}{1+\omega^{2} \tau^{2}} .
$$

In generally, the mechanical properties - storage and loss modulii are usually measured dynamically with a Dynamic Mechanical Analyzer (DMA) and modulii usually determined by testing in a pure shear mode and tests are performed in a cyclic mode. Further, in this paper, author select a fabric belt as a test belt and the basic parameter of the test belt is the following, cited in Table 1.

Table 1. Basic parameter of the test piece

\begin{tabular}{|c|c|c|c|c|}
\hline Test piece & Belt type & Width $(\mathrm{mm})-B$ & $\begin{array}{c}\text { Thickness of } \\
\text { rubber material }-h\end{array}$ & Length $(\mathrm{mm})$ \\
\hline Fabric belt & $400 * 4$ & 500 & 6 (top) +1.5 (below) & 5620 \\
\hline
\end{tabular}

\section{The Indentation Resistance Model}

The compressive forces between belt and idlers cause an indentation in the much softer material of the belt, as the idlers are generally made of a relatively hard material such as steel. Furthermore, the deformation of the idler can be ignored, because the material of idler is much harder than the material of belt. When the belt is moving over the idlers, the contact area will cause an asymmetric pressure distribution between idlers and belt, because of the viscoelastic properties of the belt material. It produces the indentation rolling resistance.

In order to discuss the indentation resistance, author firstly studies the relationship between the stationary idler and the belt. When idlers are in stationary state, the contact area is symmetric, as shown in Fig. 3.

In general, the maximum indentation depth $h_{0}$ compared to the idler radius $R$ is very small and the $h$ represents the thickness of the backing material. The contact length between belt and idler is $2 a_{0}$, when belt is in stationary state. $\left(h_{0} \ll R, a_{0} \ll R, a_{0}^{2}=2 R h_{0},-a_{0}<X<a_{0}\right)$.

The indentation amount $-Y$ at any point, whose coordinate is $\boldsymbol{X}$ on the surface of the idler is an approximated parabola as follows:

$$
\Delta Y=\sqrt{\left(R^{2}-X^{2}\right)}-R+h_{0} \approx h_{0}-X^{2} / 2 R .
$$

Hence, the compression strain of the backing material at the coordinate $X$, modelled as a Winkler foundation or independent linear elements through the backing, is as follows: 


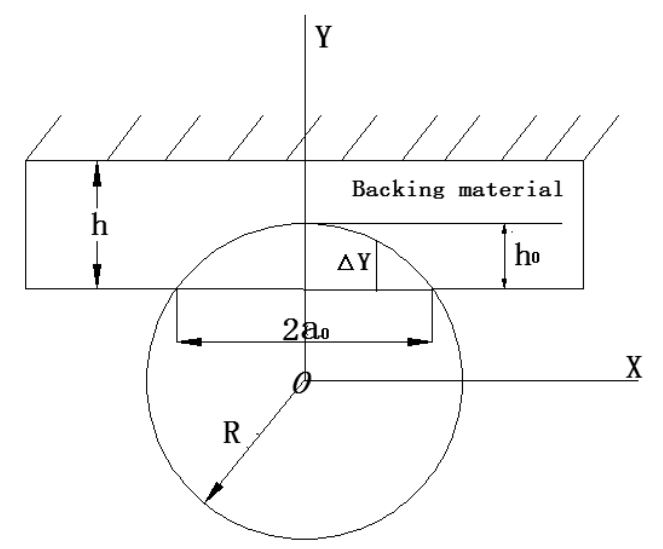

Fig. 3. Geometric model of stationary idler and belt

(9)

$$
\begin{gathered}
\varepsilon_{0}=\frac{h_{0}}{h}\left[1-\frac{1}{2}\left(\frac{\sqrt{2}}{a_{0}} X\right)^{2}\right] \approx \frac{h_{0}}{h} \sin \left(\frac{\pi}{2}-\beta\right)=\frac{h_{0}}{h} \cos \beta \\
\beta=\sqrt{2} X / a_{0}\left(-a_{0}<X<a_{0}\right) .
\end{gathered}
$$

From Equation (1) $\Psi(0)=E_{1}+E_{2}$, the compression stress between idler and belt is as follows:

$$
\sigma_{0}=\frac{h_{0}}{h}\left(E_{0}+E_{1}\right) \cos \beta .
$$

At equilibrium, the vertical load $\boldsymbol{F}_{V}$ and the resultant of the stress distribution must be in balance, such that:

$$
F_{v}=\int_{-a_{0}}^{a_{0}} \sigma_{0} d x=\frac{\sqrt{2} h_{0} a_{0}}{h}\left(E_{0}+E_{1}\right) \sin \sqrt{2} \approx \frac{a_{0}^{3}}{\sqrt{2} R h}\left(E_{0}+E_{1}\right) .
$$

There are following equations, as shown:

$$
\begin{gathered}
\sin \sqrt{2} \approx 1 \\
a_{0}=\left(\frac{\pi F_{v} R h}{2\left(E_{0}+E_{1}\right)}\right)^{1 / 3} .
\end{gathered}
$$


The contact length between belt and idler is asymmetric of the $Y$ axis, when the belt backing is passing over an idler at uniform speed $v$ (in fact the belt backing of conveyor belts varies from $0.1 \mathrm{~m} / \mathrm{s}$ to $10 \mathrm{~m} / \mathrm{s}$ ), as shown in Fig. 4. The reason which can explain the phenomenon is the viscoelastic property of backing material-rubber. As a result, the indention rolling resistance will be emerged, when the belt backing is passing over the idler.

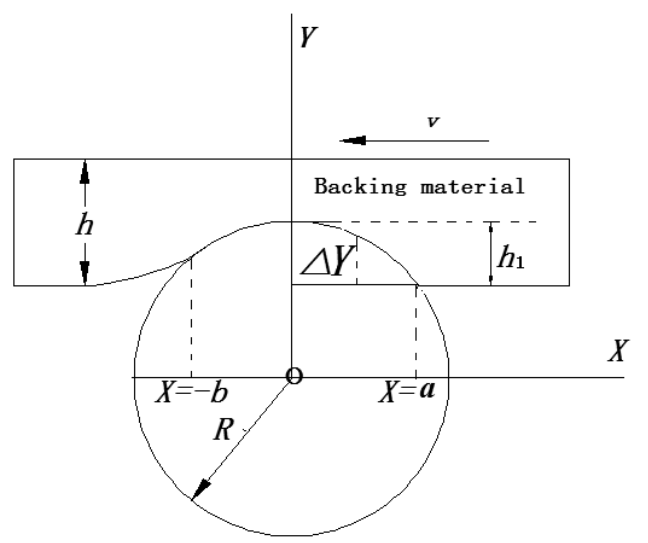

Fig. 4. Geometric model of motioning idler and belt

Generally, the value $(a+b)$ that reflect the length of contact arc between idler and belt indirectly, both the point of the first contact between idler and belt, whose $X$ axis coordinate is $X=a$ and the point of departure, whose $X$ axis coordinate is $X=-b$, is determined by the vertical load between belt and idler.

The compression strain of the backing material at the coordinate $X$ is the following and $h_{1}$ is maximum indentation depth of backing material, when belt is in motion.

$$
\begin{gathered}
\varepsilon=\frac{h_{1}}{h}\left[1-\frac{1}{2}\left(\frac{\sqrt{2}}{a} X\right)^{2}\right] \approx \frac{h_{1}}{h} \cos \beta, \\
\beta=\sqrt{2} X / a, \quad-b<X<a, \quad a^{2} \approx 2 R h_{1} .
\end{gathered}
$$

At a constant speed, the deformation process is in the essentially steady state with respect to the Eulerian coordinate $X=a-v t$, where $t$ denotes time and " $a$ " point of contact of belt and idler ( $X$ is fixed with respect to the idler, 
but not rotating with it). Using the translating coordinate speed relationship that is determined by:

$$
X=a-\nu t, \quad \frac{d x}{d t}=-\nu .
$$

The compression strain - Equation (15) may be expressed as a function of $t$, as follows:

$$
\varepsilon(t)=\frac{h_{1}}{h} \sin \left(\frac{\sqrt{2}}{a} \nu t\right) .
$$

As for a linear viscoelastic material and a one-dimensional state of stress, the stress relaxation formula for a prescribed strain history, is as follows:

$$
\sigma(t)=\int_{0}^{t} \Psi(t-\tau) \varepsilon(t) d \tau .
$$

Using the Winkler foundation model and the three-parameter Maxwell model, with coming combining Equation (1) and Equations (15) and (18), and using the following equations. It is worth noting, that when we use following equations, it will introduces about $10 \%$ difference, as a result, the formula of indentation rolling resistance will have some error:

$$
\pi / 2 \approx \sqrt{2}, \quad a^{2} \approx 2 R h_{1} .
$$

When the belt backing is passing over an idler, the compression stress, as for an arbitrary fixed point of contact area between idler and belt, may be expressed as a function of $t$ as follows:

(20) $\sigma_{y}(t)=a^{2} \frac{E_{0}}{2 R h} \frac{t \nu}{a} \frac{2 a-t \nu}{a}+\frac{a^{2} k E_{1}}{R h}\left[(1+k)\left(1-\exp \left(\frac{-t \nu}{k a}\right)-\frac{t \nu}{a}\right)\right]$.

By using the transformation $t=(a-X) / v$, the compression stress of Equation (20) can be expressed as a function of $X$ as follows, which yields the stress distribution between idler and belt backing:

$$
\begin{aligned}
\sigma_{Y}(X) & =\frac{E_{0}\left(a^{2}-X^{2}\right)}{2 R h} \\
& +\frac{a^{2} k E_{1}}{R h}\left[(1+k)\left(1-\exp \left(\frac{X-a}{a k}\right)\right)-\frac{a-X}{a}\right], k=\nu \tau / a .
\end{aligned}
$$


Now, introducing the non-dimensional length $\zeta=b / a$, it is not been ignored that the stress of Equation (20) must be equated to zero at $X=-b$, as follows:

$$
\frac{a^{2} E_{0}}{2 R h}\left(1-\varsigma^{2}\right)+\frac{a^{2} E_{1} k}{R h}\left[(1+k)\left(1-\exp \left(\frac{-1-\varsigma}{k}\right)\right)-(1+\varsigma)\right]=0 .
$$

When the belt moves at a constant speed and since the vertical load $F_{V}$ is constant for a moving belt, as a result, the load $F_{V}$ and the resultant of the stress distribution also must be in balance. Therefore we have:

$$
\begin{aligned}
& F_{v}=\int_{-b}^{a} \sigma_{Y}(X) d X=\frac{E_{0}(a+b)^{2}(2 a-b)}{6 R h}+\frac{a^{2} E_{1} k}{R h}(1+k) \\
& \times\left(a+b-k a+k \times a \times \exp \left(\frac{-b-a}{k a}\right)\right)-\frac{a k E_{1}}{R h} \frac{(a+b)^{2}}{2} \\
& F_{v}=\int_{-b}^{a} \sigma_{Y}(X) d X=\frac{a^{3} E_{0}(1+\varsigma)^{2}(2-\varsigma)}{6 R h}+\frac{a^{3} E_{1} k}{R h}(1+k) \\
& \times\left(1+\varsigma-k+k \times \exp \left(\frac{1+\varsigma}{-k}\right)\right)-\frac{a^{3} E_{1} k(1+\varsigma)^{2}}{2 R h}
\end{aligned}
$$

Then, for given material parameters $E_{0}, E_{1}, \eta_{1}$ and belt system parameters $F_{V}, R, h, v$, in order to acquire the value of indentation rolling resistance, the values of $a, b$ which must satisfy both Equation (22) and Equation (23) (24) with the load $F_{V}$ should be computed firstly. The simultaneous solution is readily accomplished numerically by a simple iterative procedure:

I. Initialize a guess for $\zeta$ (general, $\zeta=1$ ) and solve Equation (22) for $a$.

II. With the help of given material parameters $E_{0}, E 0_{1}, \eta_{1}$ and belt system parameters $F_{V}, R, h, v$, use this value of " $a$ " to solve (numerically) Equation (24) for $\zeta$.

III. Use the updated value of $\zeta$, replace the initial guess of step (I) and continue repetition of step (II), until $\zeta$ converges to a predetermined accuracy.

Following this iterative process, in order to determine an accurate value of $\zeta=b / a$, " $a$ " and " $b$ ", the moment $M$ of the stress distribution about the centre of the idler is as follows:

$$
M=\int_{-b}^{a} X \sigma_{Y}(X) d X .
$$


Then the indentation rolling resistance- $\boldsymbol{F}_{h}$ is as shown:

$$
\begin{aligned}
& F_{h}=\frac{M}{R}=\frac{a^{4} E_{0}}{8 h R^{2}}\left(\left(\frac{b}{a}\right)^{2}-1\right)^{2}+\frac{a^{4} k E_{1}}{R^{2} h} \times\left(k^{3}-\frac{k}{2}\left(1+\left(\frac{b}{a}\right)^{2}\right)\right) \\
& \frac{a^{4} k E_{1}}{R^{2} h} \times \frac{1}{3}\left(1+\left(\frac{b}{a}\right)^{2}\right)-\frac{a^{4} k E_{1}}{R^{2} h} \times k(1+k)\left(k+\frac{b}{a}\right) \times \exp \left(\frac{-a-b}{k a}\right) \\
& =\frac{a^{4} E_{0}}{8 R^{2} h}\left(1-2 \varsigma^{2}+\varsigma^{4}\right)+\frac{a^{4} k E_{1}}{R^{2} h}\left[k^{3}-\frac{k\left(1+\varsigma^{2}\right)}{2}+\frac{1+\varsigma^{3}}{3}\right] \\
& -\frac{a^{4} E_{0}}{8 R^{2} h} k(1+k)(k+\varsigma) \exp \left(\frac{1+\varsigma}{-k}\right) .
\end{aligned}
$$

From the Equation (25), the idler radius $R$, contact length $(a+b)$, the viscoelastic property of backing material $E_{0}, E_{1}, \eta_{1}$, thickness of backing material $-h$ have an effect on the indentation rolling resistance.

On the other hand, in this paper, it selects fabric belt as test belt and backing material of test belt as experimental object. What's more, in Wang F. X's paper [18], it can be seen that the viscoelastic parameters of threeparameter Maxwell model for this belt are shown as following $E_{0}=7 e 6 \mathrm{~Pa}$, $E_{1}=2.5 e 8 \mathrm{~Pa}, \eta_{1}=1875 \mathrm{Ns} / \mathrm{m}^{2}$. As a result, this paper uses those parameters to analyze the theoretical results.

\section{Analysis of theoretical results}

As mentioned above, there is a close relationship between rolling resistance and belt system parameters $F_{V}, R, h, v$. In this paper, the value of $R$ is $66.5 \mathrm{~mm}$ and the value of $h$ is $6 \mathrm{~mm}$. Author mainly concentrates on the influence of belt speed $v$ on the rolling resistance.

Generally, the belt backing of conveyor belts varies from $0.1 \mathrm{~m} / \mathrm{s}$ to 10 $\mathrm{m} / \mathrm{s}$. Therefore, we apply some representative belt speed points to the test belts $-1 \mathrm{~m} / \mathrm{s}, 2 \mathrm{~m} / \mathrm{s}, 3 \mathrm{~m} / \mathrm{s}, 4 \mathrm{~m} / \mathrm{s}, 5 \mathrm{~m} / \mathrm{s}, 6 \mathrm{~m} / \mathrm{s}, 7 \mathrm{~m} / \mathrm{s}, 8 \mathrm{~m} / \mathrm{s}, 9 \mathrm{~m} / \mathrm{s}, 10 \mathrm{~m} / \mathrm{s}$ under some fixed vertical loads $F_{V}-320 \mathrm{~N} / \mathrm{m}, 620 \mathrm{~N} / \mathrm{m}, 740 \mathrm{~N} / \mathrm{m}$, the reason why author selects those loads is that those loads $F_{V}$ can be conveniently applied to the test belt by using the test apparatus.

It can be seen from Fig. 5 and Table 2, contact length $(a+b)$ decreases nonlinearly with increasing belt speed $v$. What's more, there is a phenomenon worthy of note, that when the belt speed is in the lower level, the contact length decreases rapidly with increasing belt speed. As for this test, there is a threshold of belt speed, which is $6 \mathrm{~m} / \mathrm{s}$. When the belt speed is over the 
Investigation on Influence of Speed on Rolling Resistance ...

Table 2. Contact length $a+b(\mathrm{~mm})$ under different $F_{v}$

\begin{tabular}{|l|c|c|c|c|c|c|c|c|c|c|}
\hline$F_{V}$ & $\begin{array}{c}1 \\
\mathrm{~m} / \mathrm{s}\end{array}$ & $\begin{array}{c}2 \\
\mathrm{~m} / \mathrm{s}\end{array}$ & $\begin{array}{c}3 \\
\mathrm{~m} / \mathrm{s}\end{array}$ & $\begin{array}{c}4 \\
\mathrm{~m} / \mathrm{s}\end{array}$ & $\begin{array}{c}5 \\
\mathrm{~m} / \mathrm{s}\end{array}$ & $\begin{array}{c}6 \\
\mathrm{~m} / \mathrm{s}\end{array}$ & $\begin{array}{c}7 \\
\mathrm{~m} / \mathrm{s}\end{array}$ & $\begin{array}{c}8 \\
\mathrm{~m} / \mathrm{s}\end{array}$ & $\begin{array}{c}9 \\
\mathrm{~m} / \mathrm{s}\end{array}$ & $\begin{array}{c}10 \\
\mathrm{~m} / \mathrm{s}\end{array}$ \\
\hline $320 \mathrm{~N} / \mathrm{m}$ & 16 & 12 & 10 & 8 & 7.5 & 7 & 6.4 & 6 & 5.6 & 5 \\
\hline $620 \mathrm{~N} / \mathrm{m}$ & 22 & 17 & 14 & 12 & 10 & 9.5 & 8.8 & 8.3 & 7.8 & 7.4 \\
\hline $740 \mathrm{~N} / \mathrm{m}$ & 25 & 18 & 15 & 13 & 11 & 10 & 9.6 & 9 & 8.5 & 8 \\
\hline
\end{tabular}

Table 3. Contact length $a(\mathrm{~mm})$ under different $F_{v}$

\begin{tabular}{|l|c|c|c|c|c|c|c|c|c|c|}
\hline$F_{V}$ & $\begin{array}{c}1 \\
\mathrm{~m} / \mathrm{s}\end{array}$ & $\begin{array}{c}2 \\
\mathrm{~m} / \mathrm{s}\end{array}$ & $\begin{array}{c}3 \\
\mathrm{~m} / \mathrm{s}\end{array}$ & $\begin{array}{c}4 \\
\mathrm{~m} / \mathrm{s}\end{array}$ & $\begin{array}{c}5 \\
\mathrm{~m} / \mathrm{s}\end{array}$ & $\begin{array}{c}6 \\
\mathrm{~m} / \mathrm{s}\end{array}$ & $\begin{array}{c}7 \\
\mathrm{~m} / \mathrm{s}\end{array}$ & $\begin{array}{c}8 \\
\mathrm{~m} / \mathrm{s}\end{array}$ & $\begin{array}{c}9 \\
\mathrm{~m} / \mathrm{s}\end{array}$ & $\begin{array}{c}10 \\
\mathrm{~m} / \mathrm{s}\end{array}$ \\
\hline $320 \mathrm{~N} / \mathrm{m}$ & 8.4 & 6.1 & 5.1 & 4.1 & 3.8 & 3.6 & 3.3 & 3.2 & 2.8 & 2.6 \\
\hline $620 \mathrm{~N} / \mathrm{m}$ & 11.2 & 8.7 & 7.1 & 6.1 & 5.1 & 4.9 & 4.8 & 4.2 & 4.0 & 3.8 \\
\hline $740 \mathrm{~N} / \mathrm{m}$ & 12.9 & 9.3 & 7.7 & 6.7 & 5.7 & 5.2 & 5.1 & 4.8 & 4.4 & 4.1 \\
\hline
\end{tabular}

Table 4. Contact length $b(\mathrm{~mm})$ under different $F_{v}$

\begin{tabular}{|l|c|c|c|c|c|c|c|c|c|c|}
\hline$F_{V}$ & $\begin{array}{c}1 \\
\mathrm{~m} / \mathrm{s}\end{array}$ & $\begin{array}{c}2 \\
\mathrm{~m} / \mathrm{s}\end{array}$ & $\begin{array}{c}3 \\
\mathrm{~m} / \mathrm{s}\end{array}$ & $\begin{array}{c}4 \\
\mathrm{~m} / \mathrm{s}\end{array}$ & $\begin{array}{c}5 \\
\mathrm{~m} / \mathrm{s}\end{array}$ & $\begin{array}{c}6 \\
\mathrm{~m} / \mathrm{s}\end{array}$ & $\begin{array}{c}7 \\
\mathrm{~m} / \mathrm{s}\end{array}$ & $\begin{array}{c}8 \\
\mathrm{~m} / \mathrm{s}\end{array}$ & $\begin{array}{c}9 \\
\mathrm{~m} / \mathrm{s}\end{array}$ & $\begin{array}{c}10 \\
\mathrm{~m} / \mathrm{s}\end{array}$ \\
\hline $320 \mathrm{~N} / \mathrm{m}$ & 7.6 & 5.9 & 4.9 & 3.9 & 3.7 & 3.4 & 3.1 & 2.8 & 2.7 & 2.4 \\
\hline $620 \mathrm{~N} / \mathrm{m}$ & 10.8 & 8.3 & 6.9 & 5.9 & 4.9 & 4.6 & 4.0 & 4.1 & 3.8 & 3.6 \\
\hline $740 \mathrm{~N} / \mathrm{m}$ & 12.1 & 8.7 & 7.3 & 6.3 & 5.3 & 4.8 & 4.5 & 4.2 & 4.1 & 3.9 \\
\hline
\end{tabular}

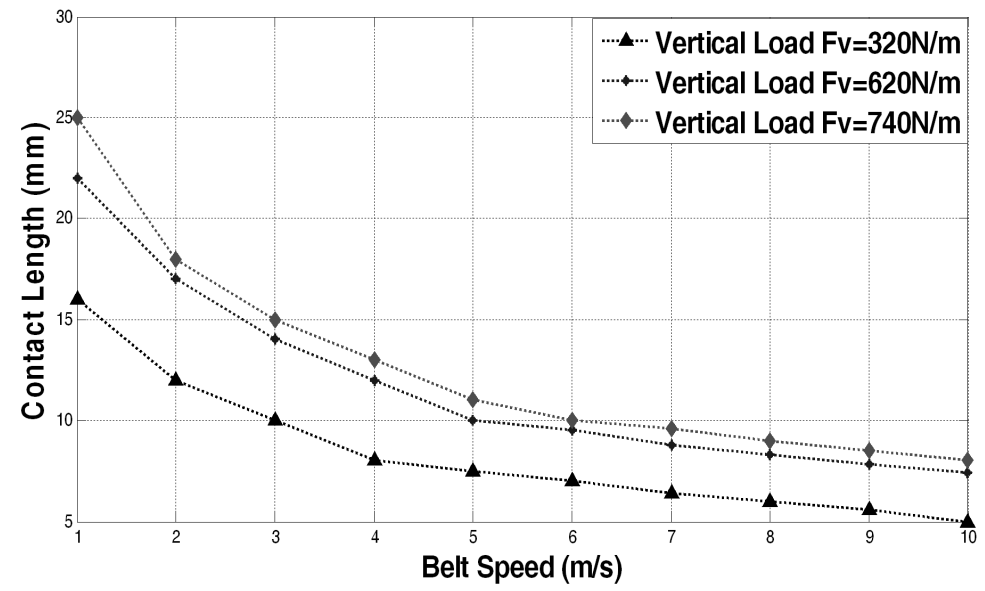

Fig. 5. Contact length $a+b[\mathrm{~mm}]$ versus belt speed $v$ at a vertical load of $320 \mathrm{~N} / \mathrm{m}$, $620 \mathrm{~N} / \mathrm{m}, 740 \mathrm{~N} / \mathrm{m}$ 
threshold, the influence of the belt speed on the contact length which has a close relationship with the value of rolling resistance is very little.

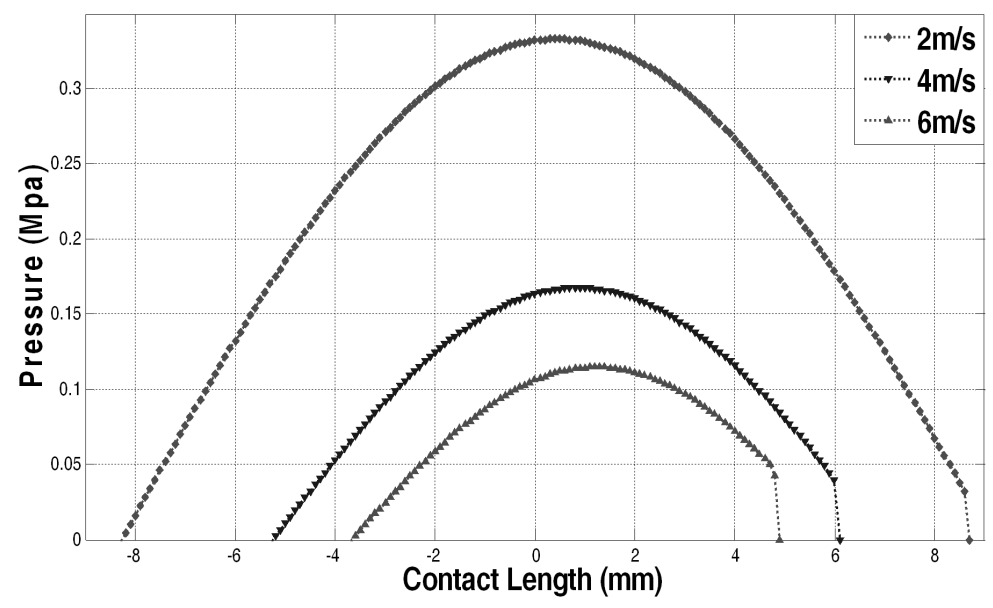

Fig. 6. Calculated pressure distribution for $133 \mathrm{~mm}$ under a simulated vertical load of $620 \mathrm{~N} / \mathrm{m}$ at belt speed of $2 \mathrm{~m} / \mathrm{s}, 4 \mathrm{~m} / \mathrm{s}, 6 \mathrm{~m} / \mathrm{s}$

From Fig. 6, it can be seen that the contact length $(a+b)$ and the peak value of stress are inversely proportional to the belt speed. What's more, it can be inferred that the compressive stress profile between idler and belt is comparatively symmetric about the centre line of the $X=0$ at a belt speed of $2 \mathrm{~m} / \mathrm{s}$. However, as the belt speed increases, the stress profile becomes more asymmetric. It is noticeable that a " hump" of the stress forms in the behind of the centre line of $X=0$.

Table 5. Indentation Rolling Resistance $F_{h}(\mathrm{~N} / \mathrm{m})$ under different $F_{v}$

\begin{tabular}{|l|c|c|c|c|c|c|c|c|c|c|}
\hline$F_{V}$ & $\begin{array}{c}1 \\
\mathrm{~m} / \mathrm{s}\end{array}$ & $\begin{array}{c}2 \\
\mathrm{~m} / \mathrm{s}\end{array}$ & $\begin{array}{c}3 \\
\mathrm{~m} / \mathrm{s}\end{array}$ & $\begin{array}{c}4 \\
\mathrm{~m} / \mathrm{s}\end{array}$ & $\begin{array}{c}5 \\
\mathrm{~m} / \mathrm{s}\end{array}$ & $\begin{array}{c}6 \\
\mathrm{~m} / \mathrm{s}\end{array}$ & $\begin{array}{c}7 \\
\mathrm{~m} / \mathrm{s}\end{array}$ & $\begin{array}{c}8 \\
\mathrm{~m} / \mathrm{s}\end{array}$ & $\begin{array}{c}9 \\
\mathrm{~m} / \mathrm{s}\end{array}$ & $\begin{array}{c}10 \\
\mathrm{~m} / \mathrm{s}\end{array}$ \\
\hline $320 \mathrm{~N} / \mathrm{m}$ & 7.4 & 5 & 4.4 & 3 & 3.06 & 2.99 & 2.66 & 2.55 & 2.13 & 1.77 \\
\hline $620 \mathrm{~N} / \mathrm{m}$ & 16 & 14.8 & 12 & 10 & 7.8 & 7.6 & 7.5 & 6.6 & 6.2 & 5.8 \\
\hline $740 \mathrm{~N} / \mathrm{m}$ & 26 & 18 & 15 & 13 & 9.9 & 9.5 & 9.3 & 8.8 & 8.0 & 7.4 \\
\hline
\end{tabular}

From Fig. 7, the influence of belt speed $v$ on the indentation rolling resistance $F_{h}$ is complex. Overall, when the belt speed is less that the threshold- 5 $\mathrm{m} / \mathrm{s}$, the rolling resistance decreases obviously with the increasing belt speed. It means, that increasing the belt speed is beneficial to reduce the rolling resistance resulting in cutting down the energy loss of belt (please, refer to Fig. 8). 


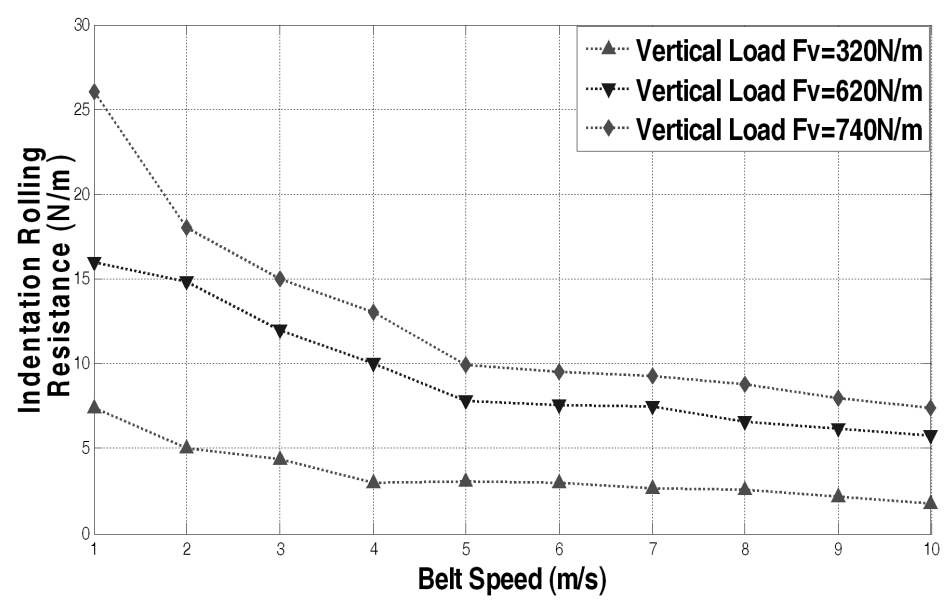

Fig. 7. Indentation Rolling Resistance $F_{h}[\mathrm{~N} / \mathrm{m}]$ versus belt speed $v$ at a vertical load of $320 \mathrm{~N} / \mathrm{m}, 620 \mathrm{~N} / \mathrm{m}, 740 \mathrm{~N} / \mathrm{m}$

However, a note worthy phenomenon is that, when the belt speed is over the threshold, the value of indentation rolling resistance plateaus even if the belt speed still increases.

\section{Experiments and verification}

In order to verify the accuracy of the theory, author needs a reliable experimental apparatus. To get reliable test data, the apparatus is built to simulate a real belt conveyor (see Fig. 8).

\subsection{Apparatus and test method}

The experimental apparatus is composed of two components that are mechanical structure and data acquisition with signal processing. On the one hand, as for the mechanical structure, it mainly consists of drive pulley, frequency converter, tension pulley, test belt, carrying flat, test idler, loading structure (please, refer to Fig. 8). Finally, the mechanical structure is shown (see Fig. 8) as follows.

On the other hand, the data acquisition with signal processing includes tension sensor,DAQ card,signal processing device, a test program of $\mathrm{PC}$ with the help of LABVIEW, that is shown as follows. It is noticeable, that the style of tension sensor is S. For as to DAQ card, it plays a role in data acquisition. The function of signal processing device is signal amplification. As for the test program, it plays a part in data acquisition, setting sampling frequency, signal filtering, storage of signal. 


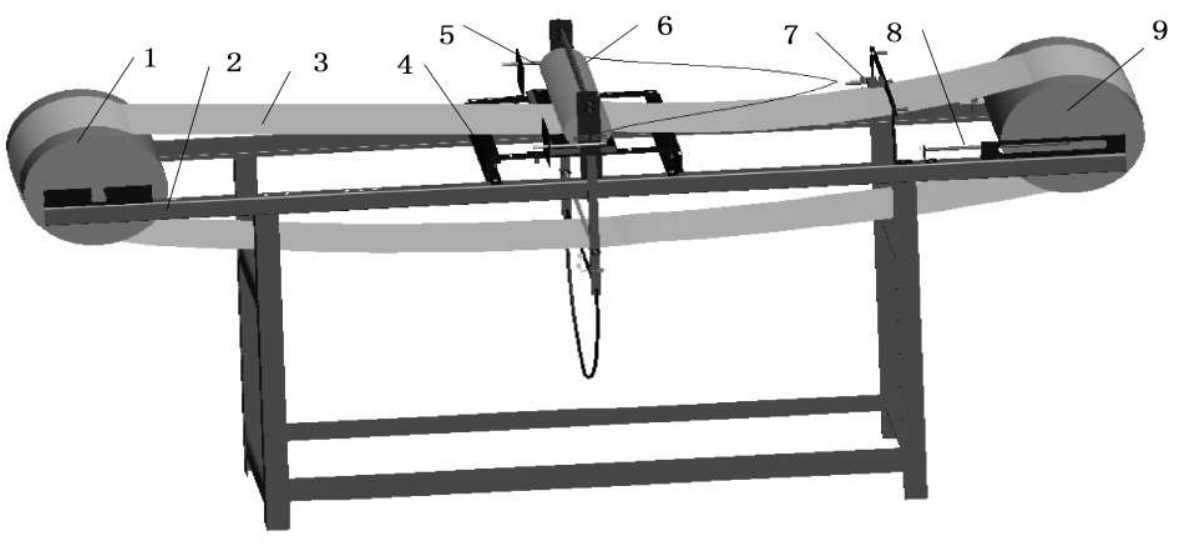

Fig. 8. Mechanical structure of experimental apparatus

1. Drive pulley 2. Body frame 3 . Test belt 4 . Load bearing mechanism 5 . Offset mechanism 6. Test idler 7. Sensor 8. Tensioning mechanism 9. Pulley

\subsection{Verification}

The parameters which can be changed are belt speed $v$, load $F_{v}$ and idler radius $R$, aimed at this experimental apparatus. In this experiment, the idler radius $R$ is $66.5 \mathrm{~mm}$. The belt speed can be changed by using the frequency converter. Different loads $F_{v}$ can be applied on the test belt with the help of loading structure.

To verify the theoretical results, author sets the belt speed $v$ at $2 \mathrm{~m} / \mathrm{s}, 3$ $\mathrm{m} / \mathrm{s}, 4 \mathrm{~m} / \mathrm{s}, 5 \mathrm{~m} / \mathrm{s}, 6 \mathrm{~m} / \mathrm{s}, 7 \mathrm{~m} / \mathrm{s}$ and sets the load $F_{v}$ at $320 \mathrm{~N} / \mathrm{m}, 620 \mathrm{~N} / \mathrm{m}, 740$ $\mathrm{N} / \mathrm{m}$, respectively. Experiments for the test belt under different loads $F_{v}$ and belt speeds $v$ are carried out. Figure 9 shows the measured and the theoretical results.

It can be seen from Fig. 9, that the test result is consistent with the theoretical result, generally. However, when the belt speed is over $5 \mathrm{~m} / \mathrm{s}$, the test data compared with the theoretical result is higher. The reason why this phenomenon is occurred may be that when the belt is in the high speed range, the apparatus will vibrate severely.

\section{Conclusion}

A theoretical analysis for the indentation rolling resistance, based on the viscoelastic property of rubber, is performed in this paper. Especially, the value of resistance for the test belt, subjected to belt speeds $v$ and loads $F_{v}$ are analyzed in detail. Ultimately, a total formula of indentation rolling resistance 


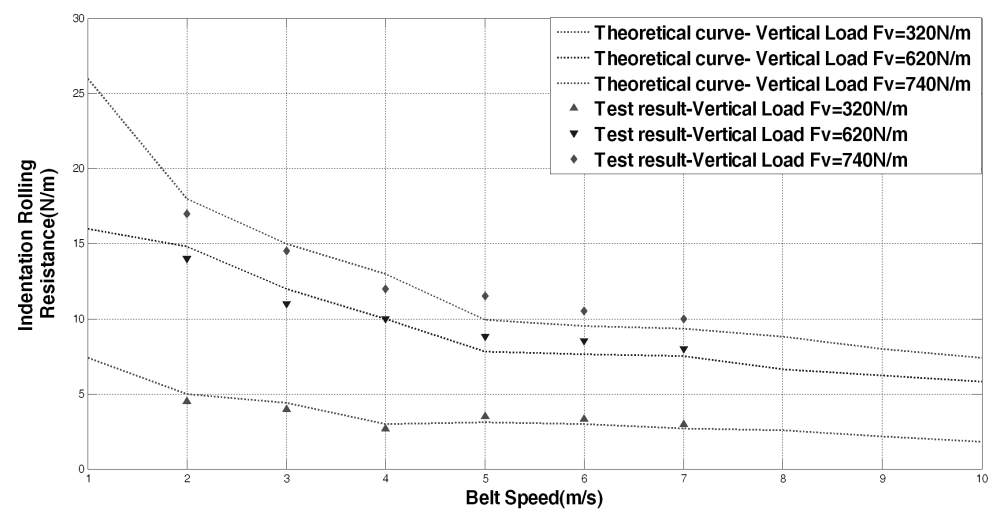

Fig. 9. Test result compared with theoretical result under different vertical loads $F_{v}$

is presented. A test apparatus, which can measure the value of indentation, is developed and experiments for test belt under different belt speeds $v$ are carried out. A comparison between the theoretical and the measured results is performed. Finally, several conclusions are derived through the theoretical analysis and the experiments.

From the formula of indentation rolling resistance, belt speed $v$, viscoelastic property of backing material of test belt $E_{0}, E_{1}, \eta_{1}$, contact length $(a+b)$ have a direct effect on the value of resistance. However, the load $F_{V}$ also has an influence on the value of resistance indirectly, by exerting influence on the contact length $(a+b)$.

The connection between the belt speed and the contact length $(a+b)$ is closely related, the contact length decreases with the increasing belt speed $v$.

The relationship between the belt speed and the indentation rolling resistance is closely linked with the threshold of belt speed $v$, it means that, under given condition, improving the belt speed $v$ can not reduce the energy belt loss.

\section{REFERENCES}

[1] Vieweg, S., R. Unger, G. Heinrich. Comparison of Dynamic Shear Properties of Styrene-Butadiene Vulcanizates filled with Carbon Black or Polymeric Fillers. Journal of Applied Polymer Science, 73 (1999), 495-503.

[2] O'Shea, J. I., C. A. Wheeler. The Influence of Viscoelastic Property Measure- 
ments on the Predicted Rolling Resistance of Belt Conveyors. Journal of Applied Polymer Science, 131 (2014), No. 18, 9710-9718.

[3] Fletcher, W. P., A. N. Gent. Non-linearity in the Dynamic Properties of Vulcanized Rubber Compounds. Trans. Inst. Rubber Ind., 29 (1953), 266-280.

[4] Ulmer, J. D. Strain Dependence of Dynamic Mechanical Properties of Carbon Black-filled Rubber Compounds. Rubber Chemistry and Technology, 69 (1996), $15-47$.

[5] Drozdov, A. D., A. Dorfmann. The Payne Effect for Particle-Reinforced Elastomers. Polymer Engineering and Science, 42 (2002), 591-604.

[6] Vieweg, S., R. Unger, K. Schroter, E. Donth, G. Heinrich. Frequency and Temperature Dependence of the Small-strain Behaviour of Carbon-black filled Vulcanizates. Polymer Networks Blends, 5 (1995), 199-204.

[7] Vieweg, S., R. Unger, G. Heinrich, E. Donth. Comparison of Dynamic Shear Properties of Styrene-butadiene Vulcanizates filled with Carbon Black or Polymeric Fillers. J. Appl. Polymer Sci., 73 (1998), 495-503.

[8] XIanguun, QIu. Full Two-Dimensional Model for Rolling Resistance: Hard Cylinder on Viscoelastic Foundation of Finite Thickness. Journal of Engineering Mechanics, 132 (2006), 1241-1251.

[9] Xianguun, QIu, C. Chai. Estimation of Energy Loss in Conveyor Systems due to Idler Identation. Journal of Energy Engineering, 137 (2011), 36-43.

[10] Wang, F. S. Indentation Rolling Resistance of Conveyor Belts based on Maxwell Model. Advanced Materials Research, 479-481 (2012), 1526-1529.

[11] Hager, M., L. Overmeyer, F. Scholl. Investigations on Causes and Value of the Indentation Rolling Resistance of Belt Conveyors. Bulk Solids Handling, 25 (2005), No. 2, 84-91.

[12] Lodewijks, G. Determination of Rolling Resistance of Belt Conveyors Using Rubber Data: Fact or Fiction? Bulk Solids Handling, 23 (2006), No. 6, 384-391.

[13] Wheeler, C. Indentation Rolling Resistance of Belt Conveyors-a Finite Element Solution. Bulk Solids Handing, 26 (2006), No. 1, 40-43.

[14] Lauhoff, H. Speed Control on Belt Conveyors - Dose it Really save Energy. Bulk Solids Handling, 25 (2005), No. 6, 368-377.

[15] Nordell, L. K. The Channar $20 \mathrm{~km}$ overland - A Flagship of Modern Belt Conveyor Technology. Bulk Solids Handling, 11 (1991), No. 4, 781-792.

[16] Jonkers, C. O. The Indentation Rolling Resistance of Belt Conveyors-A Theoretical Approach. Fördern und Heben, 30 (1980), No. 4, 312-317.

[17] Rudolphi, T., A. Reicks. Viscoelastic Indentation and Resistance to Motion of Conveyor Belts using a Generalized Maxwell Model of the Backing Material. Rubber Chemistry and Technology, 79 (2006), No. 2, p. 307.

[18] Wang, F. X., Y. F. Hou. The Research on Indentation Rolling Resistance. Mining Machinery, 38 (2010), No. 17, 75-78 (in Chinese). 